\title{
Caracterização e classificação de terras pretas arqueológicas na Região do Médio Rio Madeira
}

\author{
Milton César Costa Campos $\left({ }^{(*)}\right)$; Mateus Rosas Ribeiro $\left({ }^{2}\right)$; Valdomiro Severino Souza Júnior $\left({ }^{2}\right)$; \\ Mateus Rosas Ribeiro Filho ( $\left.{ }^{2}\right)$; Romulo Vinicius Cordeiro Conceição Souza (3); \\ Maria Conceição Almeida $\left({ }^{3}\right)$
}

(') Universidade Federal do Amazonas, Instituto de Educação, Agricultura e Ambiente, Rua 29 de Agosto, 786, 69800-000 Humaitá (AM).

(2) Universidade Federal Rural de Pernambuco (UFRPE), Departamento de Agronomia, 52171-900 Recife (PE).

(3) UFRPE, Programa de Pós-graduação em Ciências do Solo, 52171-900 Recife (PE).

(*) Autor correspondente: agromccc@yahoo.com.br

Recebido: 31/mai./2010; Aceito: 12/out./2010

\begin{abstract}
Resumo
Apesar da existência de muitas pesquisas sobre as Terras Pretas Arqueológicas, poucos são os trabalhos que têm procurado entender e esclarecer dúvidas sobre a gênese e o comportamento destes solos. Dessa maneira, o objetivo deste trabalho foi caracterizar e classificar terras pretas arqueológicas de quatro sítios na Região do Médio Rio Madeira. Nesses locais, foram abertas trincheiras e os perfis caracterizados morfologicamente e amostrados. Foram realizadas as seguintes análises físicas: textura, argila dispersa em água, densidades do solo e das partículas, porosidade total e condutividade hidráulica saturada. As análises químicas constaram de: $\mathrm{pH}$ em água e $\mathrm{KCl}$, cátions trocáveis, Al trocável, $\mathrm{P}$ disponível, acidez titulável $(\mathrm{H}+\mathrm{Al})$ e $\mathrm{C}$ orgânico, $\mathrm{Al}_{2} \mathrm{O}_{3}$ e $\mathrm{Fe}_{2} \mathrm{O}_{3}$ e $\mathrm{SiO} 2$ extraídos pelo método do ataque sulfúrico, e teor de $\mathrm{C}$ das substâncias húmicas. Para determinar óxidos de Fe foram utilizados o ditionito-citrato-bicarbonato (Fed) e o oxalato ácido de amônio (Feo). As análises mineralógicas das frações areia, silte e argila foram feitas por difratometria de raios-X. Os perfis foram classificados no Sistema Brasileiro de Classificação de Solos como: Argissolo Vermelho Amarelo, Argissolo Acinzentado e Argissolo Amarelo. Os solos apresentaram horizonte A antrópico com características químicas e de profundidade semelhantes, sugerindo certa similaridade dos fatores antrópicos que promoveram sua formação. Os horizontes antrópicos de todos os perfis amostrados na região tinham caráter eutrófico e teores altos a muito altos de fósforo disponível, sempre maiores que os dos horizontes subjacentes. Sugere-se a inclusão do subgrupo antrópico no SiBCS.
\end{abstract}

Palavras-chave: pedogênese, taxonomia de solos, SiBCS, ambiente amazônico.

\section{Characterization and classification of archaeological dark earths from the Middle Madeira River Region}

\begin{abstract}
Although several studies have been published about the Archaeological Dark Earths, few of them tried to understand and elucidate questions about the pedogenesis and behavior of these soils. Thus, the objective of this study was to characterize and classify Archaeological Dark Earths in four sites, selected in the region of the Middle Madeira River. Four pedons were morphologically characterized and collected for chemical, physical and mineralogical analysis. Physical analysis involved particle size distribution, water dispersible clay, soil bulk and particle density, total porosity and saturated hydraulic conductivity. Chemical analysis involved $\mathrm{pH}$ in water and $\mathrm{KCl}$, exchangeable cations, exchangeable aluminum, available P, extractable acidity $(\mathrm{Al}+\mathrm{H})$, organic carbon and, $\mathrm{SiO}_{2}, \mathrm{Al}_{2} \mathrm{O}_{3}$ and $\mathrm{Fe}_{2} \mathrm{O}_{3}$ extracted with $\mathrm{H}_{2} \mathrm{SO}_{4}$. Free iron oxides were extracted with dithionitecitrate-bicarbonate and poor crystalline iron oxides were extracted using ammonium acid oxalate. Mineralogical analysis of sand, silt and clay fractions were carried out by X-ray diffraction. The studied soils were classified in the Brazilian System of Soil Classification as Red Yellow Argisol, Gray Argisol and Yellow Argisol. The presence of the anthropogenic A horizons with similar chemical properties and depths in all studied sites suggests that similar conditions have influenced their formation. All anthropogenic horizons studied in the region showed high base saturation and high to very high P availability as compared to subjacent horizons. The inclusion of the anthropogenic subgroup in the Brazilian System of Soil Classification was also suggested.
\end{abstract}

Key words: pedogenesis, soil taxonomy, SiBCS, Amazon environments. 


\section{INTRODUÇÃO}

As terras pretas arqueológicas (TPA) ou Terras Pretas de Índio compreendem solos caracteristicamente de coloração escura e fragmentos de cerâmica e/ou líticos incorporados aos seus horizontes mais superficiais (KAMPF e Kern, 2005). De acordo com Glaser (2007), estes solos normalmente são de elevada fertilidade natural, com elevados teores de $\mathrm{P}, \mathrm{Ca}, \mathrm{Mg}$ e matéria orgânica estável, além de maior atividade biológica, quando comparados aos solos adjacentes. Segundo CunHA et al. (2007), a fertilidade desses solos é fortemente relacionada com as características moleculares da fração alcalino-solúvel do carbono orgânico, as substâncias húmicas.

A formação das TPAs ainda não é bem explicada, mas a hipótese mais aceita se baseia em um conjunto de evidências pedológicas e arqueológicas, sugerindo que teriam sido formadas, não intencionalmente, pelo homem pré-colombiano (Kern e Kampf, 1989). Lima et al. (2002) afirmam que as TPAs localizam-se em antigos assentamentos e que seus solos contêm artefatos culturais, são de coloração escura, devido ao material orgânico decomposto e, em parte, na forma de carvão, como resíduo de fogueiras domésticas e de queimadas para uso agrícola do solo.

Quanto à distribuição geográfica, German (2003) afirmou que estes solos distribuem-se na forma de manchas descontínuas por toda a Amazônia, estando normalmente associados aos cursos de água e a ambientes bem drenados ou em locais com posição topográfica que permitia boa visualização do terreno. Segundo Sombroek et al. (2003), as TPAs ocupam de $0,1 \%$ a $0,3 \%$ da bacia Amazônica, e as informaçôes a respeito do tamanho dos sítios variam de menos de um hectare, em terraços elevados, paralelos aos rios, a 400 hectares. Estas maiores extensões de TPA apoiam a concepção de grandes sítios de assentamentos pré-históricos ocupados por longo tempo (Kämpf e Kern, 2005).

Kern et al. (2003) relataram registros de sitios de TPA circundados por solos de cores bruno-acinzentadas e com elevado teor de matéria orgânica, porém com teores de $\mathrm{Ca}$ e $\mathrm{P}$ inferiores e menor quantidade ou mesmo ausência de artefatos de cerâmica. Esses solos possuem características diferentes dos solos não antropizados adjacentes, sendo resultantes da atividade agrícola pré-histórica, permanente ou semipermanente, sendo identificados como "terra mulata" (TM).

No SiBCS, a principal particularidade das TPAs e TMs é a presença de um horizonte A Antrópico, formado ou modificado pelo uso contínuo do homem, como lugar de residência ou cultivo por períodos prolongados, com adição de material orgânico, em mistura ou não com material mineral, contendo fragmentos de cerâmica e/ou artefatos líticos, e/ou restos de ossos e/ ou conchas.
O objetivo deste trabalho foi caracterizar e classificar Terras Pretas Arqueológicas na Regiáo do Vale Médio do Rio Madeira, Amazonas, Brasil.

\section{MATERIAL E MÉTOdOS}

\section{Caracterização do meio físico}

A área de estudo localiza-se ao sul do Estado do Amazonas, nas imediaçóes da comunidade Santo Antônio de Matupi, às margens da BR 319, rodovia Transamazônica, município de Manicoré. As coordenadas geográficas são $07^{\circ} 59^{\prime} 77,1^{\prime \prime} \mathrm{S}$ e $61^{\circ} 39^{\prime} 51,2^{\prime \prime} \mathrm{W}$, com altitude média variando entre 60 e 150 metros acima do nível do mar.

O material de origem é proveniente da alteração de granitos Rondonianos, do Pré-Cambriano Superior, sedimentos coluviais, depositados nas partes mais baixas da paisagem, e coberturas terciárias (BRASIL, 1978). O clima da região, segundo a classificação de Köppen, é do tipo tropical chuvoso, com um período seco de pequena duração $(\mathrm{Am})$, e temperaturas variando entre $25^{\circ} \mathrm{C}$ e 27 ${ }^{\circ} \mathrm{C}$, e com precipitaçôes pluviais entre 2.250 e $2.750 \mathrm{~mm}$, com chuvas concentradas no período de outubro a junho (Brasil, 1978).

O relevo é constituído por platôs com superfícies planas, sendo a zona de borda marcada por colinas e cristas alinhadas e localmente escarpadas, enquanto as áreas planas têm como principal característica a presença de uma superfície pediplanada (СРRM, 2001). A vegetação característica desta região é a Floresta Tropical Densa constituída por árvores adensadas e multiestratificadas entre $20 \mathrm{e}$ 50 metros de altura (ZeE-AM, 2008).

Foram selecionados quatro locais em posiçôes distintas da paisagem. Os perfis P1 e P3 localizam-se em posiçôes de topo, sendo o P1 sob vegetaçáo secundária (capoeira) e o P3 sob vegetação primária de floresta densa. O perfil P2 (3,5\% de declividade) localiza-se no sopé de transporte da vertente, cujo formato representa uma suave concavidade, sob capoeira, e o $\mathrm{P} 4$ (5\% de declividade), em posição de meia encosta, com suave inclinaçáo linear, sob pastagem em área recentemente desmatada e queimada para sua implantaçáo. Nesses locais foram abertas trincheiras, sendo os perfis do solo caracterizados morfologicamente e amostras de seus horizontes coletadas segundo SANTOS et al. (2005). Nelas foram realizadas análises físicas, químicas e mineralógicas. Os solos foram classificados segundo critérios estabelecidos pelo SiBCS (EMBrapa, 2006).

$\mathrm{Na}$ etapa de amostragem todo o material foi coletado (incluindo fragmentos cerâmicos e material lítico) e levado para laboratório. Após secagem ao ar as fraçóes grossas e a terra fina foram separadas e quantificadas via pesagem.

A análise granulométrica foi realizada pelo método da pipeta, utilizando uma soluçáo de $\mathrm{NaOH} 0,1 \mathrm{~N}$ como dispersante químico, e agitação mecânica em aparato de 


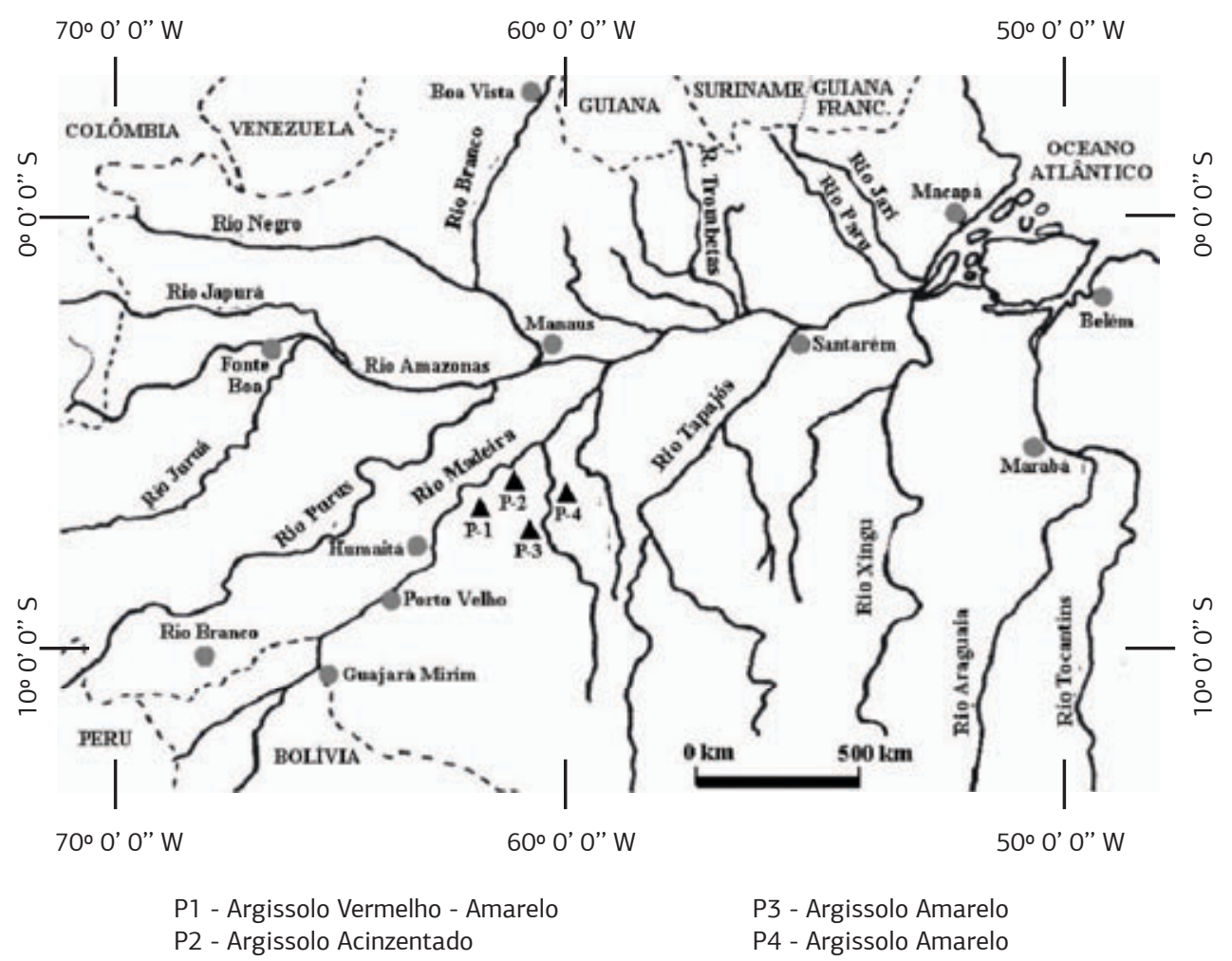

Figura 1. Mapa com a localização das áreas de ocorrência das Terras Pretas Arqueológicas (TPA), na Região do Médio Rio Madeira, Amazonas.

alta rotação por 10 minutos. A fração argila foi separada por sedimentação, as areias grossa e fina por tamisação e o silte calculado por diferença. Foi determinada a argila dispersa em água e calculado o grau de floculação, segundo EMBrapa (1997).

A densidade do solo foi obtida pelo método do anel volumétrico e a densidade das partículas pelo método do balâo volumétrico, conforme Embrapa (1997). A porosidade total foi calculada a partir dos dados obtidos das densidades do solo e das partículas, empregando-se a seguinte expressão: $\mathrm{Pt}=100(1-\mathrm{Ds} / \mathrm{Dp})$.

A condutividade hidráulica saturada dos solos foi determinada em amostras deformadas (TFSA), utilizando-se cilindro plástico com $23 \mathrm{~cm}$ de altura e $2,5 \mathrm{~cm}$ de diâmetro, com permeâmetro de carga constante. A condutividade hidráulica foi calculada conforme a lei de Darcy e expressa em $\mathrm{cm} \mathrm{h}^{-1}$ (EMBrapa, 1997).

Os elementos cálcio, magnésio e alumínio trocáveis foram extraídos com $\mathrm{KCl} 1 \mathrm{~mol} \mathrm{~L}^{-1}$; o potássio, sódio e fósforo disponível foram extraídos com solução de Mehlich-1; e a acidez potencial $(\mathrm{H}+\mathrm{Al})$ com solução tamponada a pH 7,0 de acetato de cálcio (EMBRAPA, 1997). Com base nos resultados das análises químicas foram calculadas a soma de bases (SB), a capacidade de troca catiônica (CTC) e a saturação por bases (V\%) e por alumínio.

$\mathrm{O} \mathrm{pH}$ foi determinado potenciometricamente utilizando-se relação 1:2,5 de solo: água e $\mathrm{KCl}$ (ЕмBrapa, 1997).
O carbono orgânico total foi determinado pelo método de oxidaçáo via úmida, com aquecimento externo (Yeomans e Bremner, 1988).

O fracionamento químico da matéria orgânica do solo foi executado com base na solubilidade em meio ácido e alcalino, utilizando-se $\mathrm{NaOH} 0,1 \mathrm{~mol} \mathrm{~L}^{-1}$, na relação solo: extrator de 1:20 p/v. Foram obtidas as fraçôes: ácidos fúlvicos (C-FAF), ácidos húmicos (C-FAH) e humina (CHUM), (SwIFT, 1996). O teor de carbono orgânico foi quantificado em cada fração através da oxidação utilizando solução de dicromato de potássio $0,167 \mathrm{~mol} \mathrm{~L}^{-1} \mathrm{e}$ ácido sulfúrico concentrado, com aquecimento em bloco digestor (Yeomans e Bremner, 1988). A relação C-FAH:CFAF foi obtida por cálculo.

$\mathrm{Na}$ terra fina seca ao ar (TFSA), os elementos $\mathrm{Al}$ e $\mathrm{Fe}$ foram extraídos por digestão com $\mathrm{H}_{2} \mathrm{SO}_{4} 1: 1$, e o $\mathrm{Si}$ por posterior dissolução alcalina. Os resultados foram expressos na forma de óxidos $\left(\mathrm{Al}_{2} \mathrm{O}_{3}, \mathrm{Fe}_{2} \mathrm{O}_{3}\right.$ e $\left.\mathrm{SiO}_{2}\right)$, segundo método descrito por EMBrapa (1979).

As formas cristalinas de ferro $\left(\mathrm{Fe}_{\mathrm{d}}\right)$, alumínio $\left(\mathrm{Al}_{\mathrm{d}}\right) \mathrm{e}$ silício $\left(\mathrm{Si}_{\mathrm{d}}\right)$ foram extraídas com ditionito-citrato-bicarbonato de sódio (DCB) conforme proposto por MeHra e JACKson, (1960) e os óxidos pouco cristalinos de ferro $\left(\mathrm{Fe}_{\mathrm{o}}\right)$, alumínio $\left(\mathrm{Al} \mathrm{o}_{\mathrm{o}}\right.$ e silício $\left(\mathrm{Si}_{\mathrm{o}}\right)$ por oxalato ácido de amônio (CAmargo et al., 1986).

Para as determinaçôes mineralógicas foram utilizados apenas os horizontes diagnósticos superficiais e subsuperficiais de cada um dos perfis estudados. Após as separações 
das frações areia, silte e argila, os minerais foram identificados por difratometria de raios X (DRX), empregandose difratômetro Shimadzu, operando a uma tensão de 40 kv, com corrente de $20 \mathrm{~mA}$, radiaçáo de Cuk $\alpha$, com monocromador de grafite. A amplitude de varredura foi de 5 a $70^{\circ}(2 \theta)$ e uma velocidade de registro de $3^{\circ} 2 \theta \mathrm{min}^{-1}$ para areia e silte; amplitude de 3 a $70^{\circ}(2 \theta)$ e mesma velocidade para a argila em pó. Para as amostras saturadas com $\mathrm{KCl}$ (temperatura ambiente e aquecidas a $550^{\circ} \mathrm{C}$ ) e saturadas com $\mathrm{MgCl}_{2}$ com posterior solvatação com glicerol, a amplitude de varredura foi de 3 a $35^{\circ}(2 \theta)$ e uma velocidade de registro de $2^{\circ} 2 \theta \mathrm{min}^{-1}$.

\section{RESULTADOS E DISCUSSÃO}

\section{Atributos morfológicos}

Constatou-se que em todos os horizontes antropogênicos do presente estudo havia material lítico e fragmentos cerâmicos, em quantidades que variaram de 11,8 a $310 \mathrm{~g} \mathrm{~kg}^{-1}$ (Tabela 1), corroborando os resultados observados por Kern e Kampf (1989) em áreas de TPA no Pará.

Os horizontes superficiais tinham cores úmidas variando de bruno-acinzentado muito escuro a preto, com matiz de 10YR, valores entre 2 e 3 e cromas entre 1 e 2 , enquanto os horizontes subsuperficiais, de cores amareladas ou avermelhadas, marcando uma nítida diferenciação entre o horizonte A escuro (antropogênico) e os horizontes diagnósticos subsuperficiais (Tabela 1 ).

A intensidade da cor e a profundidade de ocorrência dos horizontes antropogênicos são produtos do tempo e da continuidade da ocupação dos sítios. Assim, a pequena variaçáo na profundidade de ocorrência dos horizontes antropogênicos, entre 37 e $50 \mathrm{~cm}$, sugere que esses sítios contêm semelhanças entre si, refletindo tempo de ocupação e densidade populacional similares (Tabela 1). O mesmo foi constatado por Kern et al. (2003), os quais afirmam que a maioria das TPAs possui a espessura do horizonte A variando entre 30 e $60 \mathrm{~cm}$.

A classe de textura dos horizontes antropogênicos variou entre franco-arenosa, franca e franco-argilo-arenosa, enquanto nos horizontes diagnósticos subsuperficiais foram observadas as classes argilo-arenosa, argila e muito argilosa, corroborando com o trabalho realizado por LimA et al. (2002) em que destacam que as TPAs são bem drenadas e com textura variando de arenosa a muito argilosa, devido aos aspectos genéticos destes solos.

Os horizontes antropogênicos possuem estrutura com agregados granulares com grau de desenvolvimento forte, de tamanho variando de pequeno a muito pequeno. Este comportamento foi atribuído à ação do carbono pirogênico (particulado, livre, protegido e em complexos organo-minerais), que tem papel importante na formação e estabilização dos agregados (CunHa et al., 2007). Para os demais horizontes, a estrutura variou desde a presença de blocos angulares e subagulares nos perfis P1 e P4, a estrutura maciça moderadamente coesa nos perfis $\mathrm{P} 2$ e P3.

A consistência do solo seco nos horizontes antropogênicos variou de macia a ligeiramente dura, passando nos horizontes subsuperficiais a muito dura ou extremamente dura, justificada pela diminuição do teor de matéria orgânica e a maior quantidade de fraçōes mais finas. Para a consistência do solo úmido, observou-se nos horizontes antrópicos uma variação de friável a muito friável, enquanto nos horizontes subsuperficiais predominou a consistência firme. Para a consistência do solo molhado, observou-se que os horizontes antrópicos foram ligeiramente plásticos, em função do conteúdo de argila, sendo este mesmo comportamento observado para a pegajosidade. Nos horizontes subsuperficiais, tanto a plasticidade como a pegajosidade tenderam a aumentar proporcionalmente ao conteúdo das fraçôes finas.

\section{Atributos Físicos}

Observou-se dominância da fração areia, em particular da areia grossa no horizonte antrópico, em todos os perfis. Entretanto, verificou-se nítida variação da textura em funçáo da posição de ocorrência da TPA no relevo. No P2, em posiçấo de sopé de vertente, a textura mais arenosa provavelmente se deve à influência de materiais coluviais, provenientes das partes mais altas da encosta. Esta posição de sopé de transporte também é responsável pela coloração acinzentada do horizonte $\mathrm{Bt}$, levando a classificação do solo como Argissolo Acinzentado, tendo em vista que este ambiente favorece maior acúmulo de água. Para os demais sítios de TPA (P1, P3 e P4) há, na fração areia, contribuição de pequenos fragmentos líticos e cerâmicos, corroborando resultados obtidos por GERMAN (2003).

Em relação aos horizontes diagnósticos subsuperficiais, observou-se que, excetuando-se o perfil P2, de natureza coluvial, nos demais perfis (P1, P3 e P4) há dominância da fraçáo argila (Tabela 2) refletindo a característica argilosa dos Argissolos da regiáo, corroborando com resultados avaliados por Lima et al. (2006).

$\mathrm{Na}$ maioria dos solos da Amazônia, a argila dispersa em água possui valores mais elevados com o aumento da profundidade, corroborando com os resultados da pesquisa em questão. O grau de floculação tem maior expressão nos horizontes A antrópico, especialmente nos perfis P2 e P4. (Tabela 2). Estes resultados estão em concordância com Lima et al. (2002) os quais afirmam que em TPAs apesar das condições climáticas favoráveis à destruição dos agregados do solo, o estado de organização da estrutura é tâo fortemente desenvolvido que não propicia este comportamento. Além disso, a elevada atividade biológica e o teor de matéria orgânica, especialmente os ácidos húmico e fúlvico favorecem a maior agregação. 


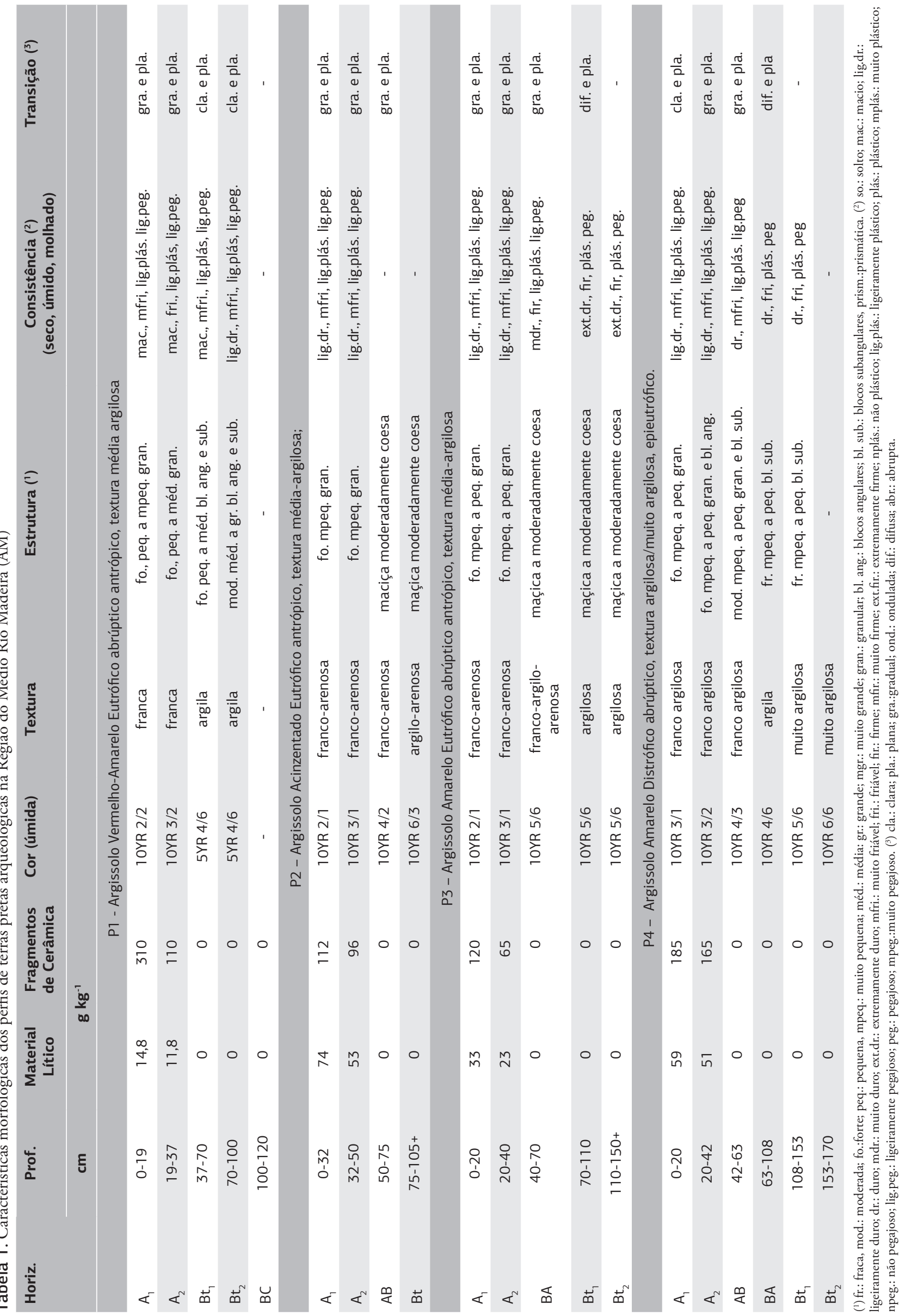


Tabela 2. Caracterização física dos perfis de terras pretas arqueológicas na Região do Médio Rio Madeira (AM)

\begin{tabular}{|c|c|c|c|c|c|c|c|c|c|c|c|c|}
\hline \multirow[t]{2}{*}{ Horizonte } & Profundidade & A.G. & A.F. & Silte & Argila & AD & G. F. & S/A & Ds & Dp & Pt & CHS \\
\hline & \multicolumn{2}{|l|}{$\mathbf{c m}$} & \multicolumn{2}{|c|}{$\mathbf{g ~ k g}^{-1}$} & \multicolumn{4}{|c|}{$\%$} & \multicolumn{2}{|c|}{$\mathrm{kg} \mathrm{dm}^{-3}$} & $\%$ & $\mathrm{~cm} \mathrm{~h}^{-1}$ \\
\hline \multicolumn{13}{|c|}{ P1 - Argissolo Vermelho-Amarelo Eutrófico abrúptico antrópico, textura média argilosa } \\
\hline$A_{1}$ & $0-19$ & 271 & 167 & 319 & 243 & 28 & 84 & 1,3 & 0,7 & 2,5 & 69 & 19,8 \\
\hline$A_{2}$ & $19-37$ & 267 & 153 & 343 & 237 & 28 & 88 & 1,4 & 0,8 & 2,7 & 69 & 14,8 \\
\hline $\mathrm{Bt}_{1}$ & $37-70$ & 123 & 95 & 261 & 521 & 36 & 93 & 0,5 & 0,9 & 2,8 & 65 & 12,2 \\
\hline $\mathrm{Bt}_{2}$ & 70-100 & 105 & 92 & 248 & 555 & 8 & 99 & 0,4 & 1,0 & 2,8 & 63 & 11,6 \\
\hline$B C$ & $100-120$ & & & & & & & & - & - & - & \\
\hline \multicolumn{13}{|c|}{ P2 - Argissolo Acinzentado Eutrófico antrópico, textura média-argilosa } \\
\hline$A_{1}$ & $0-32$ & 528 & 138 & 147 & 187 & 29 & 84 & 0,7 & 1,0 & 2,5 & 60 & 21,4 \\
\hline $\mathrm{A}_{2}$ & $32-50$ & 565 & 171 & 105 & 159 & 37 & 77 & 0,6 & 1,1 & 2,5 & 57 & 22,2 \\
\hline$A B$ & $50-75$ & 534 & 174 & 100 & 192 & 96 & 50 & 0,5 & nd & 2,5 & nd & 23,6 \\
\hline $\mathrm{Bt}$ & 75-105+ & 447 & 117 & 81 & 355 & 169 & 52 & 0,2 & nd & 2,7 & nd & 32,1 \\
\hline \multicolumn{13}{|c|}{ P3 - Argissolo Amarelo Eutrófico abrúptico antrópico, textura média-argilosa } \\
\hline$A_{1}$ & $0-20$ & 577 & 107 & 140 & 176 & 35 & 80 & 0,8 & 1,0 & 2,6 & 61 & 30,7 \\
\hline $\mathrm{A}_{2}$ & $20-40$ & 553 & 144 & 129 & 174 & 56 & 67 & 0,7 & 1,2 & 2,6 & 51 & 30,2 \\
\hline BA & $40-70$ & 352 & 127 & 144 & 377 & 136 & 64 & 0,3 & 1,5 & 2,6 & 43 & 29,7 \\
\hline $\mathrm{Bt}_{1}$ & $70-110$ & 222 & 73 & 140 & 565 & 16 & 97 & 0,2 & 1,4 & 2,7 & 48 & 28,1 \\
\hline $\mathrm{Bt}_{2}$ & $110-150+$ & 229 & 70 & 116 & 585 & 19,0 & 97 & 0,2 & - & 2,6 & - & 25,3 \\
\hline \multicolumn{13}{|c|}{ P4 - Argissolo Amarelo Distrófico abrúptico, textura argilosa/muito argilosa, epieutrófico } \\
\hline$A_{1}$ & $0-20$ & 236 & 104 & 247 & 413 & 22 & 95 & 0,6 & 0,8 & 2,6 & 68 & 24,6 \\
\hline $\mathrm{A}_{2}$ & $20-42$ & 277 & 95 & 280 & 348 & 26 & 92 & 0,8 & 0,8 & 2,6 & 68 & 24,4 \\
\hline$A B$ & $42-63$ & 195 & 104 & 307 & 394 & 24 & 94 & 0,7 & 1,0 & 2,6 & 60 & 12,5 \\
\hline BA & 63-108 & 156 & 62 & 182 & 600 & 36 & 94 & 0,3 & 1,1 & 2,7 & 59 & 9,3 \\
\hline $\mathrm{Bt}_{1}$ & $108-153$ & 121 & 53 & 189 & 637 & 15 & 98 & 0,3 & 1,1 & 2,7 & 59 & 7,8 \\
\hline $\mathrm{Bt}_{2}$ & $153-170$ & 121 & 53 & 145 & 681 & 131 & 81 & 0,2 & - & 2,74 & - & 7,5 \\
\hline
\end{tabular}

A.G. = areia grossa; A.F. = areia fina; $\mathrm{AD}=$ argila dispersa em água; $\mathrm{G} . \mathrm{F} .=$ grau de floculação; $\mathrm{S} / \mathrm{A}=$ relação silte/argila; $\mathrm{Ds}=$ densidade do solo; $\mathrm{Dp}=$ densidade de partícula; $\mathrm{Pt}=$ porosidade total $\mathrm{CHS}=$ condutividade hidráulica do solo saturado.

A relação silte/argila revelou valores semelhantes em todos os perfis estudados (Tabela 2), dados comuns em solos amazônicos.

A densidade do solo indicou valores mais baixos para os horizontes antropogênicos em todos os perfis (Tabela 2) e os valores aumentam com a profundidade. Segundo STEINBEISs et al. (2009), este comportamento é resultante dos elevados teores de carbono orgânico e de intensa atividade biológica (fauna e raízes), que constrói canais, cavidades e galerias. Por outro lado, a densidade de partícula com valores semelhantes em todos os perfis, evidencia a presença de partículas de mesma natureza mineral (Tabela 2). Já a porosidade total nos horizontes antropogênicos é mais elevada que nos demais horizontes subsuperficiais. Essa mesma tendência foi observada para a condutividade hidráulica, também devido aos elevados teores de matéria orgânica e à intensa atividade biológica (fauna e raízes).

\section{Atributos Químicos}

Os valores de $\mathrm{pH}$ em água variaram de 5,9 a 7,0 nos horizontes antropogênicos, e os de $\mathrm{pH}$ em $\mathrm{KCl}$, foram sempre menores, entre 4,8 a 6,9 (Tabela 3). Esses valores são similares aos analisados por Solomon et al. (2007), porém contrariam os valores de Moreira (2007), evidenciando a natureza heterogênea de ocorrência das TPAs, pelas con- diçóes pedoambientais e as atividades humanas em cada local.

Os teores de fósforo disponível foram elevados nos horizontes antropogênicos, entretanto com valores muito dispersos. Foram avaliados teores de 143,5 a $230,7 \mathrm{mg}$ $\mathrm{kg}^{-1}$ no P1, 15,5 a 16,9 $\mathrm{mg} \mathrm{kg}^{-1}$ no P2, 26,1 a 35,4 mg $\mathrm{kg}^{-1}$ no P3 e 24,0 a $25,7 \mathrm{mg} \mathrm{kg}^{-1}$ no P4. Estes resultados dispares são provavelmente decorrentes da intensidade da incorporação de detritos pelos antigos habitantes, conforme destacam Fraser e Clement (2008) em estudo sobre solos de TPAs na região amazônica.

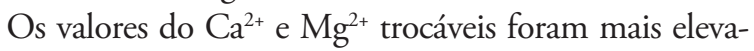
dos nos horizontes superficiais, o que está de acordo com Steiner et al. (2004), os quais afirmaram que as TPAs exibem elevados níveis de nutrientes, principalmente $\mathrm{Ca}$ e $\mathrm{P}$, provavelmente, proveniente de restos de ossos humanos e de animais, além da formação de complexos matéria orgânicacálcio, de alta estabilidade (elevados teores de Ca), associados ao carvão pirogênico (Novotny et al., 2007). Por outro lado, verificou-se que os teores $\mathrm{de}^{\mathrm{Ca}^{2+}}$ e $\mathrm{Mg}^{2+}$ variaram entre as áreas estudadas, o que pode ser reflexo da variaçáo do tempo e da densidade da ocupação humana nas áreas.

Os maiores valores de soma de bases foram observados nos horizontes antropogênicos quando comparados aos horizontes subsuperficiais. Entretanto, também foram notadas diferenças entre os perfis de TPAs estudados, com valores mais elevados nos perfis P2 e P3, de 29,9 e 26,4 


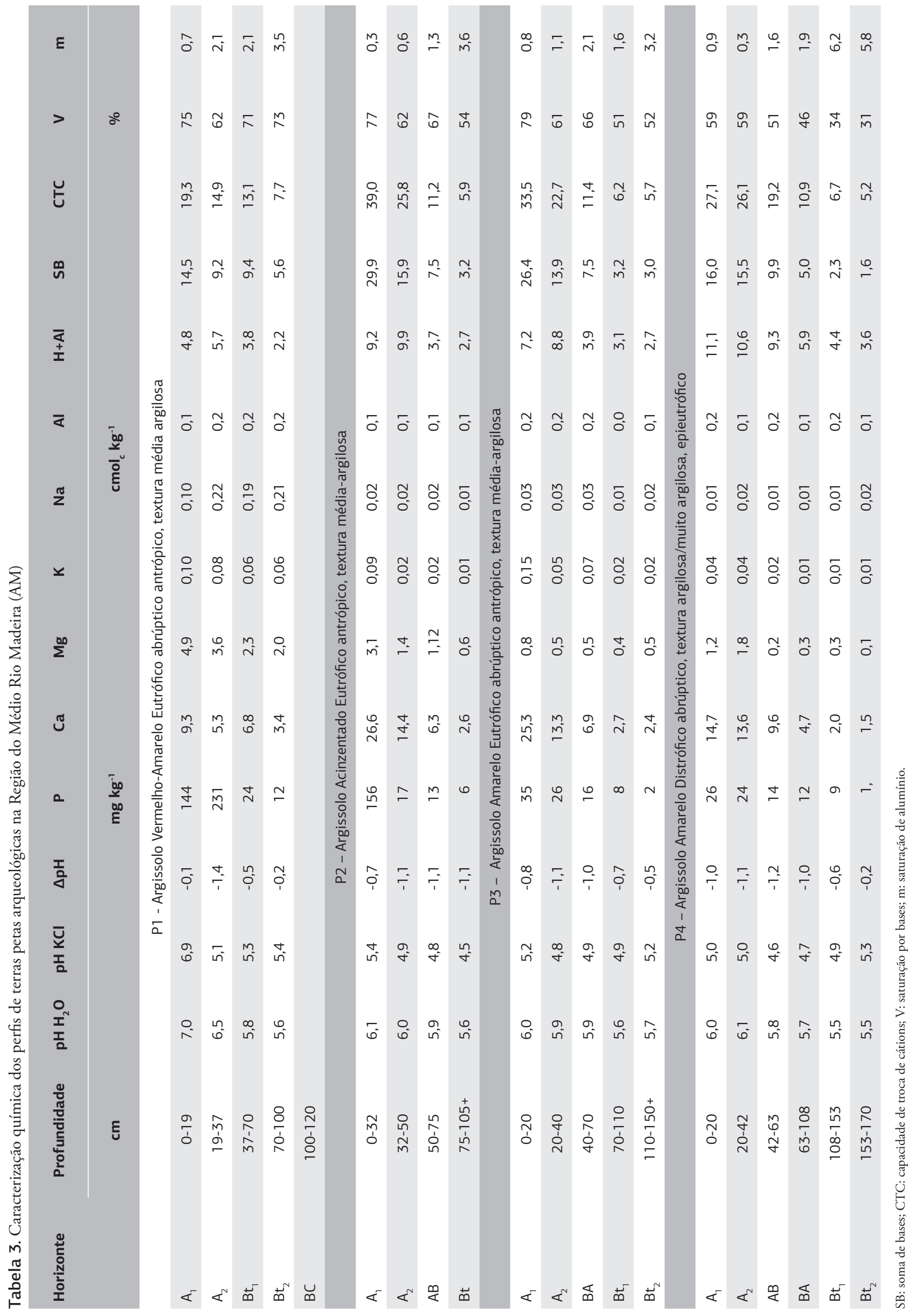


cmol $\mathrm{cg}_{\mathrm{c}}^{-1}$ respectivamente, e 16,0 e $14,5 \mathrm{cmol}_{\mathrm{c}} \mathrm{kg}^{-1}$, para os perfis $\mathrm{P} 4$ e P1, respectivamente, concordando com os resultados de LeHMANn et al. (2003).

Com relação à CTC, verificou-se também que os perfis $\mathrm{P} 2$ e $\mathrm{P} 3$ ocorrem os maiores valores quando comparados aos perfis P1 e P4. Para todos os perfis estudados há nítida tendência de decréscimo de CTC com a profundidade do solo, comportamento também observado por Glaser et al. (2000) em estudos de TPAs na Amazônia. A saturação por bases revelou valores mais elevados nos horizontes antrópicos, valendo ressaltar que nos perfis $\mathrm{P} 1$, P2 e P3 os valores do V\% foram também elevados nos horizontes subsuperficiais, comportamento que não foi observado para o perfil P4, provavelmente, o impacto da ação antrópica não se limita aos horizontes superficiais, mas pode alterar o solo em profundidade, contando com a contribuição de processos pedogênicos (melanizaçáo, lessivagem e bioturbaçáo) (Kern e Kampf, 2005).

Observou-se que os valores totais de $\mathrm{Fe}_{2} \mathrm{O}_{3}$ e $\mathrm{Al}_{2} \mathrm{O}_{3}$ tinham comportamento semelhante, com valores maiores nos perfis P1, P3 e P4, (Argissolos Amarelos e VermelhoAmarelos), e menores no P2 (Argissolo Acinzentado) (Tabela 4). Este fato deve-se, possivelmente, ao regime de umidade associado aos teores de matéria orgânica e carência do material de origem do sítio do perfil P2 que favorece a mobilização, redistribuição e exportação do ferro e alumínio na forma amorfa $\left(\mathrm{Fe}_{\mathrm{o}}\right.$ e $\left.\mathrm{Al}_{\mathrm{o}}\right)$ para outros locais, incidindo diretamente na expressão de cores de cromas mais baixos, em relação aos perfis $\mathrm{P} 1, \mathrm{P} 3$ e $\mathrm{P} 4$.

Os valores da relaçáo $\mathrm{Fe}_{\mathrm{ox}} / \mathrm{Fe}_{\mathrm{d}}$ distribuíram-se semelhantemente para todos os perfis estudados, exceção feita ao P2 com valores ligeiramente mais elevados. Este comportamento deve-se, possivelmente, às maiores quantidades de matéria orgânica, combinadas com os maiores teores de umidade dificultando assim a cristalização dos óxidos de Fe (Tabela 4). Quanto aos valores da relaçáo $\mathrm{Al} / \mathrm{Al}_{\mathrm{d}}$ verificaram-se relaçôes similares, com maiores valores da relação no $\mathrm{P} 2$, evidenciando conteúdo de $\mathrm{Al}$ ainda na estrutura dos óxidos de ferro. Segundo Demattê et al. (1994) à medida que os óxidos vão ficando menos cristalinos, em superfície, eles são mais facilmente removidos do solo e transportados para as partes mais baixas do terreno.

A relação (Fed/Fet) tem sido utilizada como indicador auxiliar do grau de desenvolvimento do solo, sendo maior nos solos mais intemperizados. No presente estudo verificou-se que os valores desta relação (Fed/Fet) são maiores nos perfis P1, P3 e P4 quando comparados ao P2, indicando que estes solos estão em estágio mais avançado de intemperismo.

\section{Atributos Mineralógicos}

Em relação à mineralogia da fração areia, nos perfis P1 e P3 verificou-se comportamento semelhante, com pre- domínio de quartzo e traços de feldspatos em seus horizontes diagnósticos, e no caso do P1 ocorreram traços de feldspato no horizonte $\mathrm{Bt}_{1}$ e no perfil $\mathrm{P} 3$ no horizonte $\mathrm{A}_{1}$. No perfil P2 notou-se maior expressão de quartzo e traços de feldspatos nos dois horizontes diagnósticos $\left(\mathrm{A}_{1} \mathrm{e} \mathrm{Bt}\right)$. Já no perfil $\mathrm{P} 4$ havia exclusivamente quartzo em ambos os horizontes diagnósticos (Tabela 5).

A composição mineralógica da fração silte é bastante semelhante, com presença marcante de quartzo e anatásio, e reflexos de feldspatos e ilmenita. Esta composiçáo mineralógica dos solos reflete, de certo modo, a pobreza de minerais máficos do material de origem (granitos e sedimentos terciários) (BRASIL, 1978), associada ao intenso intemperismo químico, que predomina na região amazônica.

A mineralogia da fração argila das TPAs é também bastante semelhante, com dominância de caulinita e gibbsita, além de traços de mica (Tabela 5), náo diferindo dos resultados analisados por Couceiro e Santana (1999) que estudaram a mineralogia de solos da Amazônia. Para Horbe e Costa (1997), essa mineralogia se repete na grande maioria dos solos bem drenados da região Amazônica brasileira, e é reflexo da pobreza do material de origem, das boas condiçóes de drenagem e do tempo de exposiçáo dos sedimentos aos agentes bioclimáticos.

\section{Carbono orgânico total e fracionamento químico da MOS}

Nos horizontes antropogênicos, os teores de carbono orgânico total (COT) oscilaram entre 43,7 e 80,3 $\mathrm{g} \mathrm{kg}^{-1}$, entre os perfis, verificando-se os maiores valores nos perfis $\mathrm{P} 2$, P1 e P3 (Tabela 6). Apesar do valor de COT estar conceitualmente superior ao limite de $8 \%$, o qual por definição seria de horizonte e/ou camada orgânica EMBRAPA (2006), esses resultados podem ser atribuídos ao carbono pirogênico (carvão) proveniente das atividades dos povos indígenas pré-colombianos, conforme destaca Glaser (2000), ou à dominância de estruturas aromáticas, com baixo grau de substituiçáo de oxigênio (CunHA et al., 2007).

Observou-se maior teor de carbono associado à fração humina (C-FHUM), seguido da fração ácido húmico (C$\mathrm{FAH}$ ), que são mais estáveis, em detrimento de carbono associado à fração ácido fúlvico (C-FAF), mais solúvel e móvel (Tabela 6). Segundo Madari et al. (2009) este fato deve-se à maior presença de grupamentos aromáticos e de anéis benzênicos, do maior grau de polimerização e menor suscetibilidade ao ataque microbiano.

Quanto aos valores da relação C-FAH/C-FAF, estes oscilaram entre 1 a 2,5, indicando predominância de melhores características do húmus, demonstrando a melhor qualidade do solo mesmo em condiçôes que favoreçam a rápida mineralização, conforme destaca Moreira (2007).

De forma geral, constatou-se que em todas as fraçôes orgânicas houve decréscimo com a profundidade do solo, 


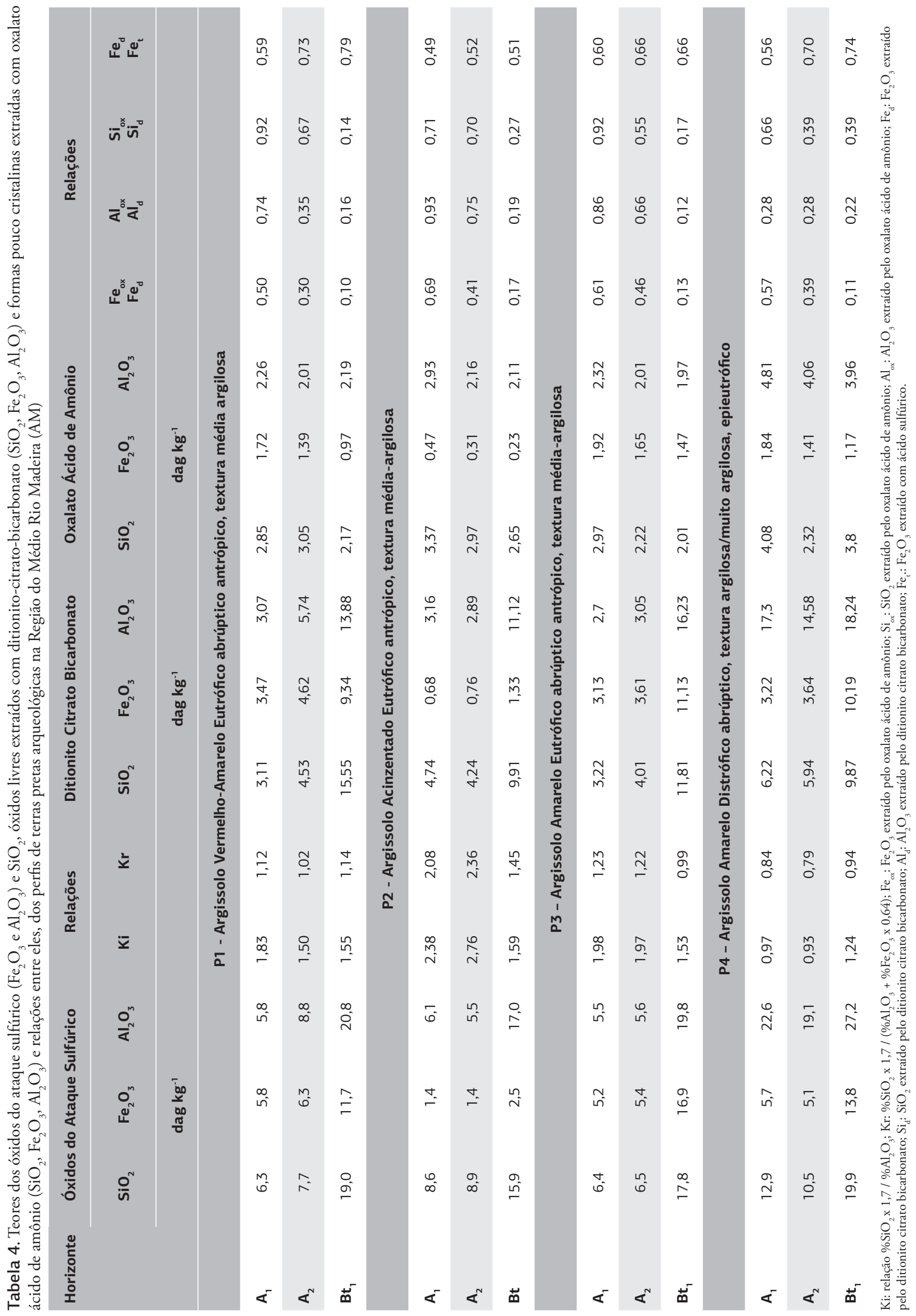


Tabela 5. Composição mineralógica das fraçôes areia, silte e argila dos horizontes diagnósticos superficiais e subsuperficiais dos perfis de terras pretas arqueológicas na região do Médio Rio Madeira (AM)

\begin{tabular}{|c|c|c|c|}
\hline Horizonte & Areia & Silte & Argila \\
\hline \multicolumn{4}{|c|}{ P1 - Argissolo Vermelho-Amarelo Eutrófico abrúptico antrópico, textura média argilosa } \\
\hline$A_{1}$ & Q & $\mathrm{Q}, \mathrm{An}, \mathrm{Fd}$ e Im & Ct e Gb \\
\hline $\mathrm{Bt}_{1}$ & Q e Fd & $\mathrm{Q}, \mathrm{An}, \mathrm{Fd}$ e Im & Ct e Gb \\
\hline \multicolumn{4}{|c|}{ P2 - Argissolo Acinzentado Eutrófico antrópico, textura média-argilosa } \\
\hline$A_{1}$ & Q e Fd & Q, An, Fd e Im & Ct e Gb \\
\hline Bt & Q e Fd & $\mathrm{Q}, \mathrm{An}, \mathrm{Fd}$ e Im & Ct e Gb \\
\hline \multicolumn{4}{|c|}{ P3 - Argissolo Amarelo Eutrófico abrúptico antrópico, textura média-argilosa } \\
\hline$A_{1}$ & Q e Fd & $\mathrm{Q}, \mathrm{An}, \mathrm{Fd}$ e Im & Ct e Gb \\
\hline $\mathrm{Bt}_{1}$ & Q & $\mathrm{Q}, \mathrm{An}, \mathrm{Fd}$ e Im & $\mathrm{Ct}$, Gb e M \\
\hline \multicolumn{4}{|c|}{ P4 - Argissolo Amarelo Distrófico abrúptico, textura argilosa/muito argilosa, epieutrófico } \\
\hline$A_{1}$ & Q & Q, An, e Im & Ct e Gb \\
\hline $\mathrm{Bt}_{1}$ & Q & Q, An, Fd e Im & Ct e Gb \\
\hline
\end{tabular}

Tabela 6. Teores do carbono total e fraçôes das substâncias húmicas: fração ácido fúlvico (C-FAF), fração ácido húmico $(\mathrm{C}-\mathrm{FAH})$ e fração humina (C-FH) e a relação entre elas das terras pretas arqueológicas, na região do Médio Rio Madeira (AM)

\begin{tabular}{|c|c|c|c|c|c|c|}
\hline Horizonte & Profundidade & C-FAF & C-FAH & C-FH & СOT & C-FAH/C-FAF \\
\hline \multirow{2}{*}{\multicolumn{7}{|c|}{$\begin{array}{l}\mathrm{cm} \\
\text { P1 - Argissolo Vermelho-Amarelo Eutrófico abrúptico antrópico, textura média argilosa }\end{array}$}} \\
\hline & & & & & & \\
\hline$A_{1}$ & 0-19 & 9,4 & 16,5 & 27,9 & 77,2 & 1,7 \\
\hline$A_{2}$ & $19-37$ & 5,8 & 15,0 & 12,4 & 62,4 & 2,5 \\
\hline $\mathrm{Bt}_{1}$ & $37-70$ & 4,7 & 7,5 & 9,4 & 19,2 & 1,5 \\
\hline $\mathrm{Bt}_{2}$ & 70-100 & 2,5 & 4,6 & 8,0 & 18,0 & 1,8 \\
\hline \multicolumn{7}{|c|}{ P2 - Argissolo Acinzentado Eutrófico antrópico, textura média-argilosa } \\
\hline$A_{1}$ & $0-32$ & 5,4 & 9,3 & 11,8 & 80,3 & 1,7 \\
\hline $\mathrm{A}_{2}$ & $32-50$ & 3,2 & 8,6 & 8,6 & 45,9 & 2,6 \\
\hline BA & $50-75$ & 2,1 & 6,4 & 8,3 & 34,1 & 2,9 \\
\hline $\mathrm{Bt}$ & 75-105+ & 1,0 & 2,1 & 7,4 & 19,4 & 1,9 \\
\hline \multicolumn{7}{|c|}{ P3 - Argissolo Amarelo Eutrófico abrúptico antrópico, textura média-argilosa } \\
\hline$A_{1}$ & $0-20$ & 6,1 & 7,2 & 15,5 & 71,0 & 1,1 \\
\hline$A_{2}$ & $20-40$ & 3,2 & 5,0 & 11,8 & 56,7 & 1,5 \\
\hline $\mathrm{BA}$ & $40-70$ & 2,1 & 3,5 & 8,5 & 18,0 & 1,6 \\
\hline $\mathrm{Bt}_{1}$ & 70-110 & 1,8 & 2,1 & 7,1 & 5,3 & 1,1 \\
\hline $\mathrm{Bt}_{2}$ & $110-150+$ & 1,0 & 0,7 & 6,2 & 4,5 & 0,6 \\
\hline \multicolumn{7}{|c|}{ P4 - Argissolo Amarelo Distrófico abrúptico, textura argilosa/muito argilosa, epieutrófico } \\
\hline$A_{1}$ & $0-20$ & 8,3 & 16,5 & 17,1 & 43,7 & 1,9 \\
\hline $\mathrm{A}_{2}$ & $20-42$ & 6,9 & 13,3 & 13,8 & 44,0 & 1,9 \\
\hline$A B$ & $42-63$ & 4,3 & 9,3 & 10,1 & 28,2 & 2,1 \\
\hline BA & 63-108 & 3,2 & 5,0 & 8,0 & 18,4 & 1,5 \\
\hline $\mathrm{Bt}_{1}$ & $108-153$ & 2,1 & 2,8 & 6,0 & 10,9 & 1,3 \\
\hline $\mathrm{Bt}_{2}$ & $153-170$ & 0,7 & 2,1 & 4,8 & 8,0 & 2,9 \\
\hline
\end{tabular}

seguindo a tendência do COT. Individualmente os teores das substâncias húmicas têm o seguinte comportamento: a) os maiores valores das três fraçōes (C-FAH, C-FAF e $\mathrm{C}-\mathrm{FH}$ ) foram encontrados nos perfis $\mathrm{P} 1$ e $\mathrm{P} 4 \mathrm{e}$ b) os menores valores observados nos perfis $\mathrm{P} 2$ e $\mathrm{P} 3$, pois nestes também ocorreram menores valores de carbono orgânico total. Estes resultados estáo acima dos avaliados por Lima et al. (2002) e foram similares aos apresentados por CunHa et al. (2007), que estudou solos antropogênicos da Amazônia.
De maneira geral, os valores da fraçáo humina (CFHUM) são elevados em solos antrópicos e não antrópicos, fato também observado neste estudo. A fração ácido fúlvico (C-FAF) foi aquela com menores valores em comparação às demais frações sendo, segundo MADARI et al. (2009), dominante em solos não antrópicos. $\mathrm{Na}$ fração ácido húmico (C-FAH), por sua vez, os valores foram expressivos. Segundo Novotny et al. (2007) e Cunha et al. (2009) as propriedades que determinam a função e as transformações dos ácidos húmicos são sua estabilidade 
(baixa decomposição e lixiviação aumentando a persistência do carbono orgânico no solo), reatividade (formação de complexos organo-metálicos, cujas ligaçôes formadas entre a fase mineral e orgânica do solo favorecem a acumulação de carbono orgânico) e suscetibilidade à mineralização no solo (quantidades das estruturas alifáticas hidrofílicas nas associações moleculares dessa fração).

\section{Classificação dos Solos}

Com base no Sistema Brasileiro de Classificação de Solos (EMBrapa, 2006), os quatro perfis foram classificados até o $4 .^{\circ}$ nível categórico, sendo utilizado para o $5 .^{\circ}$ nível o grupamento textural e o caráter epieutrófico (apenas para o perfil distrófico). No grupamento textural, a textura média foi subdividida em média-arenosa, para separar os solos com teor de argila menor que $20 \%$ e média-argilosa para os solos com teor de argila igual ou maior que $20 \%$.

Dessa maneira, os solos foram assim classificados: P1 - Argissolo Vermelho-Amarelo Eutrófico abrúptico antrópico, textura média argilosa; P2 - Argissolo Acinzentado Eutrófico antrópico, textura média-argilosa; P3 - Argissolo Amarelo Eutrófico abrúptico antrópico, textura média-argilosa, e P4 - Argissolo Amarelo Distrófico abrúptico antrópico, textura argilosa/muito argilosa, epieutrófico. As classes de solos encontradas são concordantes com as identificadas por Lima (2001), que afirma que as TPAs taxonomicamente podem enquadrar-se como Argissolos.

\section{CONCLUSÃO}

As TPAs estão adequadamente enquadradas nos diversos níveis categóricos do SiBCS. Entretanto, neste trabalho, sugere-se a inclusão do subgrupo antrópico, a exemplo do subgrupo úmbrico, utilizado para a presença de a proeminente;

$\mathrm{Na}$ área estudada nas TPAs há semelhanças nas características químicas e na profundidade do horizonte $\mathrm{A}$ antrópico, sugerindo certa similaridade dos fatores antrópicos que promoveram sua formaçáo;

Os horizontes antrópicos de todos os solos amostrados na região são de caráter eutrófico e teores altos a muito altos de fósforo disponível, sempre maiores que os dos horizontes subjacentes.

\section{AGRADECIMENTOS}

Os autores agradecem ao Conselho Nacional de Desenvolvimento Científico e Tecnológico $(\mathrm{CNPq})$ a concessão de bolsa de pesquisa ao segundo autor.

\section{REFERÊNCIAS}

BRASIL. Ministério das Minas e Energia. Projeto Radambrasil, folha SB. 20, Purus. Rio de Janeiro, 1978. 561p.

CAMARGO, O.A.; MONIZ, A.C.; JORGE, J.A.; VALADARES, J.M.A.S. Métodos de análise química, mineralógica e física de solos do IAC. Campinas, Instituto Agronômico de Campinas, 1986. 94p. (Boletim Técnico, 106)

COUCEIRO, P.R.C.; SANTANA, G.P. Caulinita em solo da Amazônia: caracterização e permutabilidade. Acta Amazônica, v.29, p.267-275, 1999.

CPRM.CentrodePesquisadeRecursos Minerais. Hidroclimatologia, geologia, recursos minerais, geomorfologia e unidades de paisagens. Manaus, 2001.93p. (Relatório Técnico)

CUNHA, T.J.F.; MADARI, B.E.; BENITES, V.M.; CANELAS, L.P.; NOVOTNY, E.H.; MOUTTA, R.O.; TROMPOWSKY, P.; SANTOS, G.A. Fracionamento químico da matéria orgânica e características de ácidos húmicos de solos com horizonte $\mathrm{A}$ antrópico da Amazônia (Terra Preta). Acta Amazônica, v.37, p.9198, 2007.

CUNHA, T.J.F.; MADARI, B.E.; CANELAS, L.P.; RIBEIRO, L.P.; BENITES, V.M.; SANTOS, G.A. Soil organic matter and fertility of anthropogenic dark earths (Terra Preta de Índio) in the Brazilian Amazon basin. Revista Brasileira de Ciência do Solo, v.33, p.85-93. 2009.

DEMATTÊ, J.A.M.; ALOISI, R.R.; DEMATTE, J.L.I. Seqüência Latossolo Amarelo - Podzólico Amarelo - Areias Quartzosas sob material da formação barreiras na região de Tucuruí, Estado do Pará. Scientia Agricola, v.51, p.345-356, 1994.

EMPRESA BRASILEIRA DE PESQUISA AGROPECUÁRIA - EMBRAPA. Centro Nacional de Pesquisa de Solos. Manual de métodos de análise de solo. Rio de Janeiro, 1997. 212p.

EMPRESA BRASILEIRA DE PESQUISA AGROPECUÁRIA - EMBRAPA. Centro Nacional de Pesquisa de Solos. Sistema Brasileiro de Classificação de Solos. Brasília, 2006. 354p.

EMPRESA BRASILEIRA DE PESQUISA AGROPECUÁRIA. Serviço Nacional de Levantamento e Conservação de Solos. Manual de métodos análise de solo. Rio de Janeiro, 1979. 247p.

FRASER, J.A.; CLEMENT, C.R. Dark Earths and manioc cultivation in Central Amazonia: a window on pre-Columbian agricultural systems? Boletim do Museu Paraense Emilio Goeldi de Ciências Humanas, v.3, p.175-194, 2008.

GERMAN, L.A. Historical contingencies in the coevolution of environment and livelihood: contributions to the debate on Amazonian Black Earth. Geoderma, v.111, p.307-331, 2003.

GLASER, B. Prehistorically modified soils of central Amazonia: a model for sustainable agriculture in the twenty-first century. Philosophical Transactions of the Royal Society B, v.362, p.187196, 2007.

GLASER, B.; BALASHOV, E.; HAUMAIER, L.; GUGGENBERGER, G.; ZECH, W. Black carbon in density 
fractions of anthropogenic soils of the Brazilian Amazon region. Organic Geochemistry, v.31, p.669-678, 2000.

HORBE, A.M.C.; COSTA, M.L. Solos gerados a partir do intemperismo de crostas lateríticas sílicoferruginosas. Acta Amazônica, v.27, p.241-256, 1997.

KÄMPF, N.; KERN, D.C. O solo como registro da ocupação humana pré-histórica na Amazônia. In: VIDAL-TORRADO, P.; ALLEONI, L.R.F.; COOPER, M.; SILVA, A.P.; CARDOSO, E.J.. (Ed.). Tópicos em Ciência do Solo. Viçosa, MG, Sociedade Brasileira de Ciência do Solo, 2005, p.277-320.

KERN, D.C.; D`AQUINO, G.; RODRIGUES, T.E.; FRAZÃO, F.J.L.; SOMBROEK, W.; NEVES, E.G.; MYERS, T.P. Distribution of antropogenic dark earths. In: LEHMANN, J.; KERN, D.C.; WOODS, W.; GLASER, B. (Org.). Amazonian dark Earths: origin, properties, management. 1.ed. Norwell: Kluwer Academic Publishers, 2003. p.51-76.

KERN, D.C.; KÄMPF, N. O efeito de antigos assentamentos indígenas na formação de solos com terra preta arqueológicas na região de Oriximiná - PA. Revista Brasileira de Ciência do Solo, v.13, p.219-225, 1989.

LEHMANN, J.; KERN, D.C.; GERMAN, L.A.; McCANN, J.; MARTINS, G.C.; MOREIRA, A. Soil fertility and production potential. In: LEHMANN, J., KERN, D.C., GLASER, B.; WOODS, W.I. (Ed.). Amazonian dark earths; origin, properties and management. Dordrecht: Kluwer Academic Publishers, 2003. p. $105-124$.

LIMA, H.N.; SCHAEFER, C.E.R.; MELLO, J.W.V.; GILKES, R.J.; KER, J.C. Pedogenesis and pre-Columbian land use of "Terra Preta Anthrosols" ("Indian black earth") of Western Amazonia. Geoderma, v.110, p.1-17, 2002.

LIMA, H.N.; MELLO, J.W.V.; SCHAEFER, C.E.G.R.; KER, J.C.; LIMA, A.M.N. Mineralogia e química de três solos de uma toposseqüência da Bacia Sedimentar do Alto Solimóes, Amazônia Ocidental. Revista Brasileira de Ciência do Solo, v.30, p.59-68, 2006.

MADARI, B. E.; CUNHA, T.J.F.; NOVOTNY, E.H.; MILORI, D.M.B.P.; MARTIN NETO, L.; BENITES, V.M.; COELHO, M.R.; SANTOS, G.A. Matéria Orgânica dos Solos Antrópicos da Amazônia (Terra Preta de Índio): suas características e papel na sustentabilidade da fertilidade do solo. In: TEIXEIRA, W.G.; KERN, D.C.; MADARI, B.E.; LIMA, H.N.; WOODS, W. (Ed.). As terras pretas de índio da Amazônia: sua caracterização e uso deste conhecimento na criação de novas áreas. Manaus: 2009. Cap. 13, p.172-188.

MEHRA, O.P.; JACKSON, M.L. Iron oxide removal from soils and clays by a dithionite-citrate system buffered with sodium bicarbonate. In: NATIONAL CONFERENCE ON CLAYS AND
CLAYS MINERALS, 7., Washington, 1960. Proceedings... New York, 1960. p.317-327.

MOREIRA, A. Fertilidade, matéria orgânica e substâncias húmicas em solos antropogênicos da Amazônia Ocidental. Bragantia, v.66, p.307-315, 2007.

NOVOTNY, E.H.; DEAZEVEDO, E.R.; BONAGAMBA, T.J.; CUNHA, T.J.F.; MADARI, B.E.; BENITES, V.M.; HAYES, M.H.B. Studies of the compositions of humic acids from Amazonian dark earth soils. Environmental Science and Technology, v.41, p.400-405, 2007.

SANTOS, R.D.; LEMOS, R.C.; SANTOS, H.G.; KER, J.C.; ANJOS, L.H. Manual de descrição e coleta de solos no campo. 5.ed. Viçosa. Sociedade Brasileira de Ciência do Solo, 2005. 100p.

SOLOMON, D.; LEHMANN, J.; THIES, J.; SCHAFER, T.; LIANG, B.; KINYANGI, J.; NEVES, E.G.; PETERSEN, J.; LUIZĀO, F.J.; SKJEMSTAD, J. Molecular signature and sources of biochemical recalcitrance of organic C in Amazonian Dark Earths. Geochimica et Cosmochimica Acta, v.71, p.2285-2298, 2007.

SOMBROEK, W.G.; RUIVO, M.L.; FEARNSIDE, P.M.; GLASER, B.; LEHMANN, J. Amazonian Dark Earths as carbon stores and sinks. In.: LEHMANN, J.; KERN, D.C.; GLASER, B.; WOODS, W.I. (Eds.). Amazonian Dark Earths: origin, properties, and management. Dordrecht: Kluwer Academic Publishers, 2003. p.125-139.

STEINBEISS, S.; GLEIXNER, G.; ANTONIETTI, M. Effect of biochar amendment on soil carbon balance and soil microbial activity. Soil Biology and Biochemistry, v.41, p.1301-1310, 2009.

STEINER, C.; TEIXEIRA, W.G.; LEHMANN, J.; ZECH, W. Microbial response to charcoal amendments of highly weathered soils and Amazonian dark earths in Central Amazonia - preliminary results. In: GLASER, B.; WOODS, W.I. (Ed.). Amazonian dark earths: explorations in space and time. New York: Springer, 2004. p.195-212.

SWIFT, R.S. Organic matter characterization. In: SPARKS, D.L.; PAGE, A.L.; HELMKE, P.A.; LOEPPERT, R.H.; SOLTANPOUR, P.N.; TABATABAI, M.A.; JOHNSTON, C.T.; SUMNER, M.E. (Ed.) Methods of soil analysis: chemical methods. Madison: Soil Science Society of America; American Society of Agronomy, 1996. vol. 3, p.1011-1020. (SSSA. Book Series, 5)

YOEMANS, J.C.; BREMNER, J.M. A rapid and precise method for routine determination of organic carbon in soil. Communication in Soil Science and Plant Analysis. v.19, p.1467-1476, 1988.

ZONEAMENTO ECOLÓGICO ECONÔMICO DO SULSUDESTE DO AMAZONAS - ZEE, AM. Zoneamento Ecológico Econômico do Sul-Sudeste do Amazonas. IPAAM, 2008. 53p. 